Sociohistórica, $n^{\circ}$ 42, e060, 2do. Semestre de 2018. ISSN

1852-1606 Universidad Nacional de La Plata.

Facultad de Humanidades y Ciencias de la Educación.

Centro de Investigaciones Socio Históricas

\title{
La realización de sondeos y encuestas de opinión pública durante la gestión del General Viola en la última dictadura militar (1981)
}

Julia Risler

Facultad de Filosofía y Letras - Universidad de Buenos Aires, Argentina

risler@gmail.com

Laura Schenquer

Instituto de Humanidades y Ciencias Sociales del Litoral (Universidad Nacional del Litoral - CONICET), Argentina lauraschenquer@gmail.com

Cita recomendada: Risler, J. y Schenquer, L. (2018). La realización de sondeos y encuestas de opinión pública durante la gestión del General Viola en la última dictadura militar (1981). Sociohistórica, 42, e061. https://doi.org/10.24215/18521606e061 


\title{
La realización de sondeos y encuestas de opinión pública durante la gestión del General Viola en la última dictadura militar (1981)
}

\author{
Conducting polls and public opinion surveys during the government of General Viola in the last military \\ dictatorship (1981) \\ Julia Risler \\ Facultad de Filosofia y Letras - Universidad de Buenos \\ Aires, Argentina \\ risler@gmail.com \\ Laura Schenquer \\ Instituto de Humanidades y Ciencias Sociales del Litoral \\ (Universidad Nacional del Litoral - CONICET), \\ Argentina \\ lauraschenquer@gmail.com
}

\section{RESUMEN:}

Los gobiernos democráticos no son los únicos que realizan esfuerzos y formulan estrategias políticas para la generación de consenso, la última dictadura cívico-militar argentina también buscó aumentar sus apoyos y disminuir los sectores disidentes. Con este trabajo cuestionamos la temprana hipótesis del empleo exclusivo del terror y la coerción por parte de este régimen, para demostrar que la población también fue gobernada mediante tecnologías de convencimiento. En este trabajo analizaremos una serie de encuestas y sondeos de opinión realizados por el gobierno en 1981 para medir el ánimo social y conformar un mapa de debilidades y fortalezas que utilizó para recuperar el direccionamiento político. El general Viola asumió un gobierno jaqueado por la crisis económica y social, y mantuvo un sondeo diario de las actitudes y juicios de la población a fin de medir y obtener información que utilizó para la construcción de estrategias comunicaciones y de propaganda.

Palabras Clave: Dictadura argentina, Encuestas, Consenso, Opinión pública, Propaganda.

\section{ABstract:}

The democratic governments are not the only ones that make efforts and formulate political strategies to generate consensus. The last Argentine civic-military dictatorship also sought to increase its supports and decrease dissident sectors. With this work we question the early hypothesis of the exclusive use of terror and coercion by this regime, and instead we show the use of convincing technologies to govern the population. In this paper, we analyze a series of surveys and opinion polls conducted by the government in 1981 to measure the social mood and define a map of weaknesses and strengths used to recover the political direction. General Viola assumed a government harassed by the economic and social crisis. He maintained a daily survey of the attitudes and judgments of the population in order to measure and obtain information that he used for the construction of communication and propaganda strategies.

Keywords: Argentine dictatorship, Polls and opinion surveys, Consensus, Public opinion, Propaganda.

\section{INTRODUCCIÓN: LOS ESTUDIOS SOBRE LOS CONSENSOS EN DICTADURA}

Hasta fechas muy recientes la historiografía sobre la última dictadura cívico militar en Argentina (1976-1983) había eludido la problemática del consenso social hacia el régimen. La imposición de la dictadura y su continuidad a lo largo del tiempo, junto a la obediencia de la población, habían sido circunscritas al funcionamiento del aparato de coerción y terror. ${ }^{1}$ En esos estudios faltaba profundizar en la existencia de otros mecanismos que comparten tanto dictaduras como gobiernos democráticos, y 
que implican el empleo de agencias y el destino de recursos para desarrollar políticas gubernamentales que permitan gestionar la "obediencia" de la población, cautivarla y convencerla para obtener así su apoyo. ${ }^{2}$

A diferencia de los primeros estudios, en los últimos años la bibliografía que aborda esta problemática es cada vez más amplia y abona poco a poco al reconocimiento de las diferencias entre el consenso original y los inducidos durante el ejercicio dictatorial del poder (Lvovich, 2006; Sirlin, 2006; Canelo, 2015; Fridman, 2008, y otros). A su vez estas nuevas indagaciones admiten que, en forma paralela al plan sistemático de represión enmarcado en el terrorismo de Estado, la dictadura buscó alcanzar de forma igualmente sistemática y coordinada un disciplinamiento "productivo" de la población como uno de los objetivos para la generación de "legitimidad". 3

Julia Risler aporta a este reconocimiento con su estudio sobre la estrategia de acción psicológica. ${ }^{4}$ Esta doctrina, propia del ámbito castrense, fue elaborada bajo el influjo de la Doctrina de Seguridad Nacional y contuvo un conjunto de técnicas, procedimientos y saberes orientados a conducir, imponer comportamientos, y modelar actitudes y valores. ${ }^{5}$ En dictadura, la acción psicológica constituyó uno de los procedimientos estratégicos desplegados por el régimen militar para lograr la participación de la población en el autodenominado Proceso de Reorganización Nacional; ${ }^{6}$ en ese sentido, se desplegó como una tecnología de gobierno de la población la cual implicó una manera de "guiar a los hombres, dirigir sus conductas, constreñir sus acciones y reacciones” (Foucault, 2007, p. 16).

Las agencias estatales responsables de su implementación fueron: la Secretaría de Información Pública (SIP), el Ministerio del Interior, la Secretaría de Inteligencia del Estado (SIDE) y los organismos de inteligencia del Ejército. Estas instituciones fueron las encargadas del "ciclo de información pública" que se iniciaba con la recopilación de información sobre el ánimo y los juicios de la población (a partir sobre todo de la realización de encuestas y sondeos de opinión), continuaba con el análisis de los datos relevados, y culminaba con el desarrollo de planes nacionales de comunicación orientados a influir y obtener apoyos sociales (Risler, 2015).

En este trabajo partimos de esta estrategia para focalizarnos en una de sus principales técnicas: los sondeos y encuestas de opinión. Nos interesa reconocer cómo a través de estos el régimen relevó en 1981 las actitudes, conductas y juicios sobre el desarrollo del Proceso. Hemos hallado este material en dos "archivos de la represión”: el llamado archivo BANADE, que contiene mayormente documentación secreta y confidencial de la SIP y de las agencias antes destacadas; y el Archivo Provincial de la Memoria de Santa Fe, que resguarda los informes producidos y recibidos por la Dirección General de Informaciones (DGI) encargada del control y la persecución ideológica en la provincia. ${ }^{7}$ El abordaje simultáneo de estos dos archivos nos permitió reconocer el ciclo de esta herramienta de medición del ánimo social. Desde la elaboración de cuestionarios por la SIP o SIDE, luego su aplicación por los propios miembros de estas agencias o por las delegaciones de la SIDE en todo el país y otras agencias de la "comunidad informativa" tal como la DGI (Dirección General de Informaciones) de Santa Fe, así como también por miembros de Télam, la agencia de noticias oficial con presencia en todo el territorio nacional; y finalmente, el retorno de los sondeos y encuestas de opinión a la SIP para el análisis de la información obtenida y la preparación de informes que, bajo el título "evaluaciones y efectos psicosociales detectados en la opinión pública", explicitaban recomendaciones al Poder Ejecutivo sobre formas de acción y comunicación para captar e influir a la población y mejorar la aceptación y capacidad gubernamental de acompañamiento. En este trabajo analizaremos este accionar de la SIP y SIDE específicamente en el año 1981.

\section{LA UTILIZACIÓN DE SONDEOS Y ENCUESTAS DE OPINIÓN DURANTE LA ÚLTIMA DICTADURA}

En un libro pionero sobre el uso de encuestas y sondeos de opinión en la política argentina, el investigador Gabriel Vommaro afirma que la primera vez que se emplearon masivamente estos "instrumentos de 
legibilidad y de orientación" fue en 1983, para conocer las intenciones de voto en las elecciones presidenciales realizadas luego de siete años de dictadura (2008, p. 17). El autor señala que en ese momento los sondeos se consolidaron "como instrumentos de legibilidad y de orientación (...) como principios cognitivos en la lucha y como herramientas simbólicas para participar en ella" (2008, p. 17), ya que representan "formas de medición objetivas que permiten mantener una posición de pretensión neutra" (2008, p. 106). Paralelo a este proceso, el autor señala el avance de la privatización de medios de comunicación y la profesionalización de la actividad periodística y su conversión en "voceros de la gente frente a los políticos" (2008, p. 18) mediante la publicación de "encuestas exclusivas" que revelaban las preferencias de los encuestados.

Antes que en los institutos privados de opinión pública, las encuestas de opinión fueron utilizadas por las empresas de estudios de mercado (como A\&C, el Instituto de Psicología Social Aplicada - Ipsa, o la filial local del instituto Gallup). ${ }^{8}$ En el período previo al regreso democrático, Vommaro señala que el uso de sondeos y encuestas con fines políticos era casi inexistente, y cita un estudio de Sergio Waisbord (1995) que sostiene que hasta la década de 1980 las encuestas de opinión para medir las intenciones de voto eran raramente utilizadas en el ámbito político. Sin embargo, señala dos sondeos muy puntuales: el que la firma A\&C realizó en marzo de 1973 y dio ganador a la fórmula Cámpora-Solano Lima; y el encomendado por el régimen militar encabezado por Onganía en 1966, el cual paradójicamente le encargó a esa misma empresa medir el grado de apoyo al nuevo gobierno de facto.

El autor destaca que a partir del golpe del 76 las encuestas volvieron a ser "un producto de consumo privado" y los sondeos representaron "una herramienta de control social", mientras que, a pesar de que algunas empresas realizaron estudios para el régimen militar, estas no circularon por fuera del entorno de las fuerzas armadas $(2008$, p. 74 ). Sin embargo, y a contrapelo de una lectura instalada, el gobierno militar iniciado en marzo de 1976 también hizo uso de esta herramienta.

En este artículo no pretendemos realizar una reflexión sistemática acerca de cómo se construye una encuesta o el modo en el cual el planteo de una pregunta puede inducir la respuesta. Tampoco nos detendremos en analizar el modo en el cual los dirigentes y funcionarios del gobierno militar influyeron en su diseño, pues esto será materia de otro artículo que estamos elaborando. Fundamentalmente nos interesa cuestionar la idea de un uso gubernamental excepcional de los sondeos y encuestas de opinión en el período inmediatamente anterior a 1983. Planteamos su uso sistemático, no para evaluar candidatos como se la empleó en la primera contienda electoral tras la dictadura, pero sí para medir la opinión de la población acerca del régimen militar durante todo el período, con la pretensión de conocerla e influenciarla para captar su apoyo y participación. Así como también cuestionamos el planteo de que los resultados de las encuestas y sondeos no trascendieron más allá de la esfera de las Fuerzas Armadas, ya que hemos podido comprobar que llegaron incluso a los medios de comunicación masivos (Gente, Siete Días, Somos, etc.), los cuales, llamativamente, publicaron encuestas y sondeos propios que coincidían temporalmente con los temas abordados por la SIP y la SIDE en informes que circularon en forma secreta y confidencial. ${ }^{9}$

Cabe destacar que nuestro reconocimiento del uso sistemático de esta herramienta no fue una casualidad. Teniendo en claro el alcance nacional y programático que tuvo la estrategia de acción psicológica, en cuya bibliografía teórica se explicita la necesidad de empleo de sondeos y encuestas de opinión, ${ }^{10}$ fuimos a los archivos en busca de estas herramientas que sirvieron para reunir información sobre las actitudes de la población. Y allí estaban. El hallazgo de esta documentación nos permitió confirmar que la última dictadura utilizó este instrumento con fines políticos y a partir de objetivos concretos. ${ }^{11}$

Hemos distinguido a los documentos hallados en dos tipos: instrumentos de medición elaborados (a) por la SIP y (b) por la SIDE:

La SIP trazaba anualmente cronogramas de investigaciones incluyendo un plan de sondeos y encuestas a efectuar durante todo el año. Su realización era derivada a otras agencias (SIDE y Télam) y la información obtenida era analizada por la propia secretaría a través sus dependencias: la Dirección General de Inteligencia Psicosocial y el Centro de Investigación Psicosocial Aplicativa. 
En ese plan se indicaba realizar:

a.1. sondeos mensuales: elaborados para medir periódicamente la variación de la opinión pública sobre un número fijo de temáticas que le interesaban al gobierno. Los resultados eran volcados en informes en los que se detallaban aspectos formales (sobre cómo eran configuradas las muestras y las preguntas realizadas con las diferentes opciones de respuesta), y la interpretación que la SIP proponía de los resultados así como también "las acciones recomendadas" para revertir las tendencias desfavorables y aumentar las favorables sobre el accionar del régimen (Risler, 2015). Para el presente análisis contamos con el "Sondeo Mensual sobre aspectos de la realidad nacional. 15 de Agosto - 14 de Septiembre. 1981”, realizado por Télam a 262 personas en Capital Federal y en las principales ciudades del país.

a.2. encuestas nacionales y especiales: a diferencia de los anteriores, las encuestas no eran realizadas sistemáticamente para determinar la variación de la opinión pública, sino que se efectuaban sobre problemas o temas específicos de trascendencia para la gestión dictatorial. Estos informes también incluían detalles de las muestras y de las encuestas, así como un análisis de los resultados. Contamos para nuestro análisis con la “Encuesta nacional sobre Diálogo Político" de 1980, realizada a 8.643 personas en diferentes ciudades del país.

a.3. informes de "Situación Psicosocial": de elaboración semanal, reunían la información de los sondeos y encuestas anteriores, y la particularidad era que también incluían el análisis de los medios de comunicación. El objetivo era ofrecer al Poder Ejecutivo "indicadores" que influían o pudieran influir en la actitud y comportamiento de la población. Hemos encontrado ocho de estos informes titulados "Situación Psicosocial” realizados entre marzo y noviembre de 1981 y que son relevantes para esta investigación.

Por su parte, la SIDE efectuaba:

b.1. sondeos diarios y quincenales: en localidades pequeñas o grandes, sobre muestras de diverso tamaño, abordando temáticas específicas o construyendo un panorama informativo de temas más generales. La Dirección de Comunicación Social de la SIDE analizaba y elaboraba extensos informes (que describían datos de la muestra y de las preguntas y respuestas). A través de la realización sistemática de sondeos de opinión pública, la SIDE cumplió con su principal responsabilidad: la producción continuada de informes de inteligencia sobre la ciudadanía (Risler, 2015). Para este trabajo contamos con el "Sondeo de Opinión Pública" realizado a 2600 personas por la SIDE, entre el 14 y 21 de octubre de $1982 .{ }^{12}$ Asimismo, sabemos que en junio de 1981 la SIDE (a través de su Instituto de Investigaciones de la Opinión Pública) solicitó a la DGI de Santa Fe realizar el Sondeo "Discursos PEN en Santa Fe", ${ }^{13}$ y que en noviembre de 1981 personal de dicho instituto viajó a la ciudad capital de esa provincia para efectuar la "Encuesta Motivaciones Políticas II". Por el momento no contamos con los resultados de estas dos últimas mediciones.

Al momento de analizar estos documentos, no dejamos de pensar en las dificultades que tantos teóricos han presentado sobre los sondeos y encuestas de opinión como herramienta de inteligibilidad social (Vommaro, 2008, pp. 15-24; Bourdieu, 1973 y 2000; Maioli, 2013; Cheresky, 1998; Vinuesa Tejero y Fernández, 2014), sobre todo teniendo en cuenta que los que analizaremos fueron realizados en un contexto dictatorial que seguramente condicionaba a los encuestados (Crenzel, 2013). Asimismo, si bien contamos con las preguntas realizadas, no sabemos si eran todas o una selección sesgada a los fines de cada informe, y si las opciones de respuesta eran exactamente las mismas que se les proponía a los encuestados o si, en cambio, sólo estamos viendo una agrupación y simplificación conforme a lo que le interesaba resaltar a la SIP (Carassai, 2013, p. 123). A pesar de estas advertencias metodológicas que nos llevan a ser conscientes de la posibilidad de incurrir en un análisis desacertado, nos interesa mostrar este material y proponer un análisis en tanto evidencia el interés gubernamental por conocer los estados de la opinión pública ante las acciones del régimen; y a su vez, muestra la utilización de la información reunida en estrategias comunicacionales con las que se esperaba modificar las actitudes de la población. Esos fueron los usos concretos que los funcionarios y especialistas en la materia dieron a los resultados obtenidos. Ambos propósitos nos llevan a reconocer la existencia de una dimensión "productiva" (no ya coercitiva ni represiva) de la dictadura, orientada a regular 
los comportamientos y actitudes de la población a través del control y difusión de información y propaganda, pero también de la creación de políticas culturales y educativas orientadas en este mismo sentido.

\section{El conteXto: Viola llega A la PRESIDENCiA}

La elección del General Roberto Viola en reemplazo del presidente Videla, no fue una expresión de acuerdo entre el Ejército, la Armada y la Aeronáutica, sino más bien evidenció la lucha interna y elevada fragmentación del elenco gubernamental (Fontana, 1984; Quiroga, 2004, pp. 205-206). Viola representaba la continuidad de la "línea videlista", al menos así lo creyó el propio presidente Videla y los sectores que lo apoyaban. Al igual que este, Viola era miembro del Ejército -y de las tres fuerzas, esta fue la que ocupó las sucesivas presidencias y los ministerios estratégicos, lo que implicó su prevalencia en el esquema de poder pese a una configuración de división tripartita e igualitaria entre las tres armas (Canelo, 2012)-, y participó del golpe de Estado de 1976 como jefe de esta fuerza. Dos años más tarde integró la Junta Militar que acompañó a Videla en su segundo mandato, tras el desplazamiento del almirante Massera. ${ }^{14}$ Pero a diferencia de Videla y de la fracción "moderada" 15 que lo apoyaba, Viola había sido refractario al modelo económico liberal instalado por el ministro de Economía Martínez de Hoz (por su pertenencia a los sectores industrialistas del Ejército), lo que motivó que su designación y sus primeras declaraciones sobre la política económica fueran desacreditadas y cuestionadas por este ministro. Asimismo, los “duros" ${ }^{16}$ obstaculizaron desde el comienzo la llegada de Viola a la presidencia pero por otros motivos: sostenían la permanencia de las Fuerzas Armadas hasta refundar la Argentina (para este sector, las Fuerzas Armadas debían reformar la Constitución y asumir el rol de “árbitro" en un futuro gobierno democrático) y consideraban erróneo y arriesgado para este proyecto que Viola propusiera entablar un "diálogo" con los civiles, indicando que sería incapaz de congelar los reclamos sociales de apertura política.

A pesar de estas diferencias, y varios meses más tarde de lo previsto, finalmente el 3 de octubre de 1980 Videla anunció que el General Viola asumiría la presidencia en marzo. Si la lucha por la sucesión había culminado, a partir de las primeras declaraciones públicas de Viola antes de asumir el cargo, comenzaron los trascendidos, rumores y especulaciones: ¿Qué implicaba su mención a no modificar "los principales principios" del modelo económico y a pesar de esto indicar que realizaría "ajustes para reactivar el aparato productivo"? ¿A qué se refería al señalar que su gobierno buscaría la "normalización" de los partidos políticos"? ¿Continuaría el "diálogo" con los sectores amigos del Proceso o se entablaría un espacio de negociación cívico-militar real en el que se acordarían los plazos de entrega del poder? Y, finalmente, ¿qué pasaría con el peronismo sobre el cual Viola declaró que le demandaría "estructurarse y participar de la vida política nacional"? ${ }^{17}$

\section{LOS PROS Y LOS CONTRAS DE LA NUEVA GESTIÓN}

El primer sondeo realizado por el gobierno de Viola mostraba que la situación económico-social era el área donde se concentraban "los mayores índices de escepticismo, relativa fe y dudosa confianza" por parte de la población. Viola asumió la presidencia enfrentando un contexto internacional adverso y un frente interno enmarcado por la crisis bancaria iniciada un año atrás con el quiebre del BIR, dificultades potenciadas por la merma en las reservas del Banco Central cuyos fondos estaban siendo utilizados para subsidiar el sistema financiero. Con la asunción de la nueva gestión, el ministerio de economía fue desdoblado en cinco carteras, y los primeros anuncios del ministro de Economía Lorenzo Sigaut lograron "amplia repercusión". Al menos la opinión pública, de acuerdo a los sondeos realizados, se mostró "prudente" aunque "expectante y esperanzada" (SIP, 23/03 al 14/04/81). 
El gobierno abandonó la "tablita” cambiaria y devaluó la moneda, refinanció los pasivos de las empresas y emitió un Bono de Consolidación para financiar al sector productivo endeudado en dólares, todo esto con un elevado costo fiscal (Novaro y Palermo, 2003, p. 367). Sin embargo, todas las medidas económicas adoptadas durante esos meses fueron ineficientes y la situación económica empeoró vertiginosamente. El desempleo, los bajos salarios y una inflación que alcanzó el 131\% interanual signaron el creciente malestar social, y las protestas frente a las devaluaciones y la crisis financiera eran compartidas tanto por empresarios como por sindicalistas.

¿Cuáles eran los temas que según la SIP generaban mayor preocupación en la ciudadanía? La cuestión del aumento salarial tanto para el sector estatal como para el privado, era sin dudas el mayor tema de "tensión social" agravada por el alto desempleo, los despidos masivos y la desocupación (SIP, 06 al 12/05/81). Si bien para la SIP el problema económico impulsaba la crisis entre la opinión pública, era la cuestión laboral la que agudizaba el "problema social" e indicaba el "permanente deterioro" de la situación. ${ }^{18}$ Esta evaluación llevó a la SIP a recomendar mayores apariciones de Viola aludiendo al tema salarial. Los sondeos habían relevado que los encuestados reaccionaban favorablemente en los momentos en que aparecía Viola impartiendo instrucciones al equipo económico por el tema salarial; valoraban positivamente esta actitud y reconocían que se le estaba brindando importancia al tema, al mismo tiempo que señalaban que esto apuntalaba la función "ejecutiva y decisional" del presidente. ${ }^{19}$

Otros temas de preocupación social, relevados fuera de la situación laboral, eran la falta de expectativas de reactivación del aparato productivo y los acontecimientos de nuevas alzas en el mercado financiero y cambiario. Recordemos que, en ese momento, había una marcada preferencia social por la compra de divisas extranjeras a pesar, o quizás a causa de, los anuncios del ministro Sigaut, quien luego de afirmar que "el que apuesta al dólar, pierde” implementó una devaluación del 30\% en un intento desesperado por atraer la inversión internacional. Esta maniobra brusca y evidente, no sería fácilmente olvidada. La SIP lo sabía y por ello indicó:

durante varios meses más y posiblemente hasta mediados del año que viene (...) el gobierno no tendrá para ofrecer al país otra cosa que paciencia y esperanza en un contexto de caída de la demanda y del ingreso, desocupación y creciente y justificado descontento. ${ }^{20}$

Todos los informes de la SIP muestran que las mediciones sobre las acciones de gobierno en materia económica pasaron de ser opiniones "prudentes y expectantes" a "escépticas" incluso sobre el futuro respecto de la "evolución de la situación económica". ${ }^{21}$ No obstante, Viola intentó recomponer la base de legitimidad y trazar alianzas con militares y civiles: los partidos políticos y las organizaciones sindicales. En los sondeos hemos encontrado los temas que medían bien y que fueron estratégicamente convertidos en los "caballitos de batalla" de su gestión para recuperar la legitimidad del régimen y consolidar el apoyo civil: por un lado, la "imagen" presidencial y por el otro, el "diálogo" cívico-militar. A través de los medios masivos, el nuevo presidente de facto fue instalado como un militar "dialoguista" y con un perfil "negociador". De los primeros cuatro años de una gestión de gobierno "sin personalismos" y con fomento a la imagen de una "dictadura institucional" coherentemente impulsada por el conjunto de las Fuerzas Armadas, se pasó a la construcción y difusión de la figura de Viola convertido en el militar dispuesto a recobrar la confianza de la sociedad. El segundo tema o recurso utilizado sistemáticamente fue el "diálogo cívico-militar", que fue difundido no sólo como instancia de negociación con los civiles sino de "participación" civil en el gobierno dictatorial.

La nueva gestión realizó cambios a nivel político-económico pero no logró mejorar o resolver los principales problemas en el corto plazo. Se trató de una coyuntura signada por niveles altos de inflación, de especulación cambiaria y de volatibilidad financiera, que impactaron en el ánimo social y en buena medida explican el fin de la primera gestión militar, la brevedad del segundo mandato y el derrumbamiento final del régimen. Como ya mencionamos, aunque el desastre económico se sostuvo invariablemente, al comienzo de la gestión de Viola la opinión pública manifestaba tener "expectativas” en el gobierno. A este núcleo 
de esperanzas fue al que apuntó el plan del gobierno, lo que nos permite analizar la importancia del nivel comunicacional incluso para una dictadura. ${ }^{22}$

\section{EL IMPACTO EN LA OPINIÓN PÚBLICA DEL “DIÁLOGO CÍVICO-MILITAR” Y DE LA POSIBLE PARTICIPACIÓN DE LOS PARTIDOS POLÍTICOS}

Pese a ser considerado la "continuidad de la línea videlista", Viola en sus primeros meses como presidente anunció una serie de cambios clave, entre ellos que "los partidos políticos son los instrumentos válidos para canalizar las inquietudes ciudadanas" (Quiroga, 2004, p. 226). Se trataba de una clara diferencia con respecto a la gestión anterior encabezada por el sector "moderado", la cual además de mantener la suspensión de la actividad política inició un diálogo cívico-militar que no incluyó a los partidos y terminó siendo sumamente limitado; ${ }^{23}$ y, a la vez, implicaba rechazar las amenazas de los sectores "duros" que presionaban para evitar el acercamiento a los civiles entendiendo que la continuidad del régimen estaba garantizada.24 (Error 3: La referencia debe estar ligada) (Error 4: El tipo de referencia es un elemento obligatorio) (Error 5: No existe una url relacionada)

Viola contaba con "datos duros" de la realidad que le permitían evaluar "el diálogo" de la gestión anterior y reconocer que era un instrumento que gozaba de consenso. En 1980 la SIP realizó la "Encuesta Nacional sobre diálogo político". A lo largo de 17 provincias fueron encuestadas 8.643 personas, una muestra para nada despreciable. Los datos desagregados y el análisis de los mismos por parte de los funcionarios de la SIP conformaron un informe de 27 páginas. Entre la conclusiones más importantes se detallaba que, del total de consultados, un contundente 73\% indicaba estar de acuerdo con el "diálogo" cívico-militar. No obstante, buena parte de los mismos manifestaba no tener en claro cuál era la finalidad del gobierno al convocarlo: sólo el 46,8\% respondió que el objetivo con el que fue anunciado buscaba "instrumentar las coincidencias básicas necesarias a la solución política del país”, mientras que el resto $(61,2 \%)$ indicó que no sabía, no contestó o respondió que el "diálogo establecerá pautas para una próxima convocatoria electoral”, opción que la SIP definía errónea, pues traducía "las expectativas" de los encuestados sobre algo que el gobierno nunca había comunicado. Más allá de este problema, el informe concluía que el contundente consenso social a favor del diálogo no se traducía en el reconocimiento de los civiles convocados. El 50,1\% de las personas declaró "no sentirse representada" por los convocados al diálogo (SIP, 1980). ${ }^{25}$

Era evidente que una reedición del "diálogo" en 1981 debía realizar una convocatoria más amplia, que reconociera sin condicionamientos e impulsara la participación de los partidos políticos. Tal vez Viola no podía evitar el freno a las expectativas de apertura política pero sí podía postergarlas, estableciendo un canal de diálogo que entusiasmara a la población con la convocatoria y sedujera a las instituciones partidarias otorgándoles su legalización tal como estaban constituidas.

El llamado del gobierno a los representantes tradicionales de la sociedad y la promesa de legalizarlos (anunciada en términos de su "normalización" por medio de la aprobación del Estatuto de los Partidos Políticos, algo que tantas veces había sido manifestado públicamente y postergado) formó parte de una nueva estrategia del régimen frente a los civiles. Así como también fue parte de la misma que Viola aumentara la participación de estos en el gobierno ( 7 de los 13 ministerios fueron conducidos por civiles) y un número considerable de gobernaciones pasaron a ser ocupadas por referentes de partidos políticos provinciales. ${ }^{26}$ La nueva gestión buscaba "evitar el aislamiento" y a la vez pretendía generar alianzas con los sectores civiles y militares mencionados que corrigieran la falta de apoyo unánime del frente interno. En esta situación, el peronismo volvió a ser un actor clave y fue incluido en la reedición del "diálogo" en 1981, pero su participación quedó fuertemente condicionada ante la amenaza de los "duros" antiperonistas y la presión social de la que nos ocuparemos más adelante. 
La pregunta que nos hacemos es ¿̨podemos saber qué opinaba la población respecto a los partidos políticos? ¿los consideraba sus representantes, o la estrategia del régimen fue promocionarlos para revertir ese $50 \%$ que en 1980 manifestó no sentirse representado por los "invitados" al primer diálogo organizado en la gestión de Videla? De acuerdo con una encuesta realizada por la SIP a 500 personas en Capital Federal entre el 8 y 10 de abril de 1981, si bien casi el 60\% consideraba que Viola inauguraba una etapa de mayores libertades políticas, sólo poco más del 30\% pensaba que los partidos políticos eran los instrumentos válidos para representar a la población. ${ }^{27}$ Estos números no nos permiten sacar conclusiones generales (por un lado, la muestra de 500 personas encuestadas resulta sumamente limitada y, por el otro, la SIP citó en su informe algunas preguntas y respuestas de la encuesta sin incluir otras especificaciones), sin embargo a partir de ellos podemos admitir la posibilidad de que en ese contexto específico el anuncio de Viola sobre el impulso a alcanzar una condición de "normalización" de la situación de los partidos, no despertó expectativas. ${ }^{28}$ La respuesta del $40 \%$ de los 500 encuestados no había sido que no confiaba en el "diálogo" convocado por el gobierno, sino que no creía en los partidos políticos como representantes de sus intereses (cifra que pasa al 67\% si a las respuestas negativas les sumamos las que indicaron que los partidos los representan "más o menos", los que no sabían y los que no respondieron).

Posiblemente tampoco otras organizaciones despertasen mayores expectativas, como el proyecto fallido de reemplazar a los partidos con una estructura única, el Movimiento de Opinión Nacional. Pero ello no quita que los partidos tampoco hayan gozado en 1981 de apoyo ni reconocimiento social, tal vez como consecuencia de la desilusión generada al haber sido incapaces en 1976 de ofrecer una salida bajo el gobierno democrático a la crisis previa al golpe de Estado; situación agravada durante todos esos años de actividad política "suspendida", años que implicaron una militancia más cerrada en la semilegalidad, y que propiciaron un mayor distanciamiento entre las dirigencias partidarias y las masas simpatizantes (Yannuzzi, 1996, p. 343). ${ }^{29}$ Por lo tanto, y contestando a la pregunta respecto a que si el vuelco de Viola hacia el reconocimiento y "normalización" de los partidos se trató de una demanda social o de una estrategia gubernamental impuesta para gozar de interlocutores, podría plantearse la hipótesis de que más bien fue lo segundo, y que en marzoabril de 1981 los partidos gozaban de poco apoyo social.

En particular las declaraciones oficiales de Viola sobre el peronismo refuerzan esta hipótesis. En su primer discurso como presidente, al impulsar a los partidos como instrumentos válidos para representar a los ciudadanos, reconoció al peronismo como una identidad política mayoritaria y arraigada en amplios sectores de la población. No obstante indicó que, de participar del "diálogo", debería "emprender la democratización". La SIP midió la recepción de esta declaración, y sorprendentemente los resultados indicaron que había tenido un "impacto positivo" y la población la apoyaba. De hecho fue uno de los diez temas del primer discurso de Viola como presidente, que la SIP ponderó como los mejores recibidos por la opinión pública:

(...) la mención que el Sr. Presidente hiciera con respecto a que el peronismo deberá emprender la democratización del movimiento, para poder acceder a la calidad de interlocutor válido, fue interpretada como una aclaración y ampliación de lo expresado por el ministro del Interior. Todo ello llevó cierta tranquilidad a diversos sectores de la opinión nacional, favorables al Proceso o no, que ven en el movimiento peronista una seria amenaza para la vida nacional y sus instituciones, a menos que se encare decididamente su reestructuración (SIP, 29/03/81 al 14/04/81 itálica agregada). ${ }^{30}$

Es posible establecer una correlación directa en la población entre los índices de baja representatividad de los partidos políticos y el favorecimiento a condicionar la "normalización" del peronismo al cumplimiento de ciertos requisitos. Del mismo modo que ambos temas sugieren la desafección partidaria, el hecho de que el "diálogo político" no figurase entre los diez temas que mejor fueron recibidos, conforma otro dato relevante. 31 Esta situación marcaba una gran diferencia respecto de 1980 cuando a través de la "Encuesta Nacional sobre diálogo político" el régimen relevó que un 73\% apoyaba al "diálogo"; cifra que, tal vez, haya sido uno de los motivos para reeditar esta instancia y mejorarla a través de la admisión de los partidos políticos como mediadores de los intereses sociales. Pero la estrategia de Viola fue fallida: si la pequeña encuesta de 1981 
puede tomarse como una muestra representativa de la sociedad, entonces cabe admitir que la convocatoria a los partidos no logró asegurar la legitimidad de los convocados y, por el contrario, decayó el interés social en la instancia de "diálogo" establecida por el régimen para ampliar las bases de su sustentación.

A diferencia del primer diálogo, se observa que el segundo careció de interés social desde el comienzo y su concreción a lo largo de la gestión de Viola no logró revertir esta situación. El informe de mayo de 1981 indicaba que la razón fundamental que afectaba este asunto tenía que ver con la propia interna militar. A través de los medios de comunicación, la población estaba al tanto de los rumores que indicaban "que las relaciones entre la Junta Militar y el PEN son tensas y que existen hondas diferencias de criterio para la administración y conducción del gobierno", y que grupos y sectores militares en oposición a Viola estaban manteniendo contactos que "pasaría[n] a constituir, aparentemente, un diálogo paralelo al que llevaría a cabo el Gral. Liendo" (SIP, 06/05/81 al 12/05/81). El diálogo impulsado por Viola fue sobre todo resistido por la Junta Militar -integrada por el general Galtieri, el almirante Lambruschini y el brigadier Graffigna- a través del documento "Orientaciones No 2 de las Bases instrumentales para la acción de gobierno" (Canelo, 2015), un ejemplo de la tensión que fue constante y que terminó llevando a la caída de Viola. La instancia que el gobierno había elegido para intentar construir su apoyo careció del respaldo del frente interno, y nunca llegó a seducir a la población. En agosto, a cinco meses de iniciada la gestión Viola, la SIP indicó que estaba totalmente desacreditado: "el diálogo cívico-militar anunciado por el gobierno no despierta expectativas en el hombre común, que ya vió agotado gran parte de su interés en la instancia anterior realizada el año pasado" (SIP, 12 al 18/08/81).

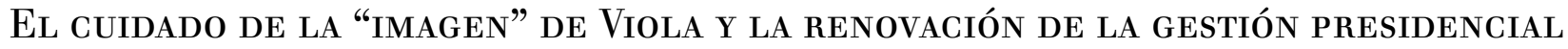

Pese al desastre económico, Viola asumió su cargo el 29 de marzo de 1981 con una opinión pública favorable:

generó en amplios sectores, en especial los de carácter político, amplias expectativas en cuanto a la necesidad de organizar política y socialmente el país como paso previo a la participación de los partidos, sindicatos y demás organizaciones, en la vida activa nacional (SIP, 29/03 al 14/04/81).

No sólo el informe de la SIP destacaba un "efecto psicosocial favorable" por las expectativas de cambio y de mayores libertades en el régimen político, sino sobre todo indicaba que para los medios de comunicación “produjo un impacto favorable, dado lo novedoso de la actitud". ¿Qué era lo novedoso de esta nueva figura presidencial? Fundamentalmente la percepción de que Viola era diferente a Videla, y el informe así lo indicaba: "existe en diversos sectores de la ciudadanía la sensación de un cambio en la tónica empleada hasta el presente; lo cual genera una amplia expectativa y es periódicamente remarcado por los MCS [medios de comunicación] formadores de opinión” (SIP, 29/03 al 14/04/81).

Asimismo la SIP remarcaba en el informe que, en una encuesta de opinión realizada en la ciudad de Buenos Aires sobre un universo de 500 personas, un 59,8\% de encuestados manifestó que Viola inauguraba una "conducción distinta a la desarrollada por la gestión anterior". La SIP relevó cuáles eran los elementos que la población entendía como parte de ese "nuevo enfoque": por un lado, la "dinámica" conducción presidencial y la "fluida" comunicación con los medios y, por el otro, que Viola iba a gobernar "sin sectarismos ni preferencias", afirmación que funcionaba como una contracara a la gestión Videla, aunque, curiosamente, Viola había sido elegido precisamente por su cercanía al expresidente de facto y como una forma de dar continuidad a los lineamientos estratégicos emprendidos por su antecesor (SIP, 29/03 al 14/04/81).

La SIP incluyó el perfil "dialoguista" entre los diez temas que mejor midieron en la primera aparición de Viola como presidente, el cual fue destacado junto a las promesas de disminución del gasto público, la supresión de organismos en la administración pública y la privatización de empresas del Estado; la atención a los cuestionamientos en torno a la situación de los derechos humanos; la solución a la situación del 
movimiento justicialista; la promesa de mejora de las relaciones internacionales, y una predisposición al diálogo frente a las inquietudes en materia laboral.

Nos interesa destacar que la SIP culminaba cada informe con evaluaciones y recomendaciones, y frente a las críticas y debilidades de la gestión de Viola que se relevaron en mayo, a cinco semanas de su asunción, insistió en fortalecer las "acciones comunicacionales" que eleven los niveles de aparición presidencial. El informe semanal de la SIP indicaba que los encuestados ya manifestaban sus primeras críticas y un desencantamiento frente a la posibilidad de que la nueva gestión pudiese revertir la situación crítica que atravesaba el país: las opiniones señalaban un gobierno "inmóvil" y con "dudas e indefiniciones en cuanto a políticas" y mostraban la "apatía, confusión y escepticismo [de la población] con respecto al futuro" debido a que el gobierno no estaba produciendo "hechos favorables en cantidad y magnitud". No obstante, todavía el 52,7\% de los encuestados "estima[ba] prematuro dar un juicio sobre la gestión presidencial", por lo cual el informe concluía que el Ejecutivo detentaba un "aval temporario", traducido en "expectativas" para desarrollar su gestión (SIP, 6/05/81 al 12.05.81). Sobre este factor operó la SIP y se tradujo en el impulso a la figura presidencial.

Uno de los aspectos que de forma permanente afectó a la imagen de Viola fue la sospecha de una gestión presidencial dependiente, subsumida a las decisiones y designios de la Junta Militar. Del mismo modo que con el diálogo político, otras definiciones de Viola fueron fracasando por esa tensión interna. El informe ya citado advierte la expansión de una ola de rumores dirigida a "desestabilizar" al gobierno, "provocar sospechas, plantear dudas y friccionar o tensionar los distintos estamentos del poder”, sobre todo en lo referido al vínculo entre la Junta Militar y el Ejecutivo, pero también al interior de las mismas Fuerzas Armadas, en donde los medios señalaban "desinteligencias" entre los diferentes sectores militares. Tampoco ayudaba a la imagen de Viola el rol de los "asesores presidenciales": según el informe los medios de comunicación se encontraban preocupados debido a "actitudes poco claras" en relación a sus funciones, las cuales rebasarían los límites de la asesoría invadiendo otras áreas de competencia y tornando confusa la estructura del poder, "sumamente cuestionada en los últimos tiempos". Frente a esta ola de rumores y a fin de evitar una imagen de debilidad y tensión al interior del gobierno, el informe sugería que los funcionarios que debían hablar públicamente estuvieran bien asesorados para transmitir información correcta y eludir un "rebote negativo" (SIP, 6 al 12/05/81).

En ese contexto, la SIP salió a relevar el apoyo de la población al "Proceso de Reorganización Nacional" y a la gestión del Poder Ejecutivo Nacional como si se tratara de dos temas independientes. Los resultados mostraban a una población dividida con respuestas de adhesión y rechazo cuantitativamente similares: un 44,2\% no apoyaba al Proceso, y un 42,4\% sí lo hacía, porcentajes que evidencian una leve diferencia a favor de los primeros; ${ }^{32}$ mientras que esa relación se revertía al responder sobre el Ejecutivo: con un apoyo del 43,8\% frente al 38\% que no apoyaba la gestión presidencial (SIP, 12 al 18/08/81). Sin embargo esta leve diferencia favorable a la figura de Viola, no debe soslayar el rechazo y el resquebrajamiento cada vez mayor en relación a las expectativas de la nueva gestión, que menguaron el apoyo de la población. Estos resultados fueron reconfirmados por nuevos informes de la SIP que especificaban las cuestiones que inquietaban o preocupaban a la población, ${ }^{33}$ e indicaban que entre mayo y septiembre las opiniones positivas sobre la gestión presidencial se habían reducido a la mitad. ${ }^{34}$

En este punto es interesante analizar la batería de recomendaciones que la SIP desplegó intentando recrear la situación de partida, utilizando los medios de comunicación que manejaba para aumentar los juicios favorables y reducir las opiniones negativas. El sondeo mensual de agosto-septiembre indicó que para "reconstruir la confianza en la gestión del Teniente General Viola" se necesitaba elevar la presencia de Viola en los medios y enfatizar los rasgos de su gestión:

- El pleno ejercicio de autoridad que el cargo le confiere, y del poder de decisión presidencial.

- La ejecutividad de la gestión -en contraposición a la 'lentitud deliberativa' que en ocasiones se le asigna-.

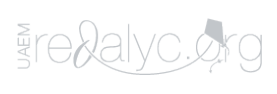


- La claridad en las definiciones de los objetivos de su gestión, y en la especificidad de los medios a ellos conducentes (“Sondeo Mensual sobre aspectos de la realidad nacional”, 15/08 al 14/09/81).

Pero la "suerte estaba echada" y los consejos de la SIP no lograron revertir la evidencia de una debacle inminente. Sólo la propia SIP parecía querer negarlo. Durante la semana previa a la licencia por enfermedad de Viola, el informe de la SIP manifestaba que, en lo referente a la gestión de gobierno, no se registraron "hechos relevantes que afecten el factor psicosocial". Esta declaración resulta muy llamativa, así como también el modo en que se minimizó la importante crisis institucional reduciéndola a que existía nuevamente una "ola de rumores" que reflejaba sentimientos de ansiedad, inseguridad y desconfianza sobre el gobierno, "exacerbada por las constantes versiones de renuncias en su seno, que llegan hasta la figura del Presidente de la Nación” (SIP, 28/10 al 03/11/81). Este informe se distanciaba de la realidad y de que tan sólo una semana más tarde Viola pediría una licencia por enfermedad, tras la cual la Junta Militar aprovecharía para declararlo incapacitado a ocupar su cargo. El comandante Leopoldo F. Galtieri, de la línea "dura” y opuesto al diálogo cívico-militar y a la apertura democrática, asumió el 11 de diciembre la presidencia en su reemplazo.

\section{A MODO DE CONCLUSión}

Nuestro trabajo muestra la importancia y el uso sistemático que el régimen militar le brindó a los sondeos y encuestas de opinión para ponderar el estado de ánimo general de la población sobre las acciones del gobierno, y determinar los pasos a seguir para disminuir las críticas y aumentar los sectores de apoyo. Sobre todo nos concentramos en su empleo en el año 1981, y reconocimos la estrategia comunicacional delineada a través del impulso a la imagen de un presidente "dialoguista y negociador", dispuesto a establecer nuevas alianzas y a corregir errores del pasado, al mismo tiempo que utilizaba el "diálogo" cívico-militar como una instancia de participación civil en el régimen. Los asesores presidenciales de la SIP, sin poder revertir la profusión de juicios críticos ante la incapacidad en el manejo de la situación económica, buscaron reducir sus efectos y para ello reforzaron los medios en los que la "imagen" y el "diálogo" de Viola parecían responder a las "expectativas de la gente". Fue una maniobra que funcionó al menos los primeros meses, dio un "aire" que sin duda le quitaron las propias discusiones con el frente interno.

Pero estos temas, "imagen” y "diálogo", que efectivamente en algún momento del inicio de la gestión de Viola "medían bien” ¿hasta qué punto pueden ser utilizados para revertir la situación de un régimen deslegitimado y en pleno derrumbe? Con esta pregunta no hacemos más que reponer el interrogante de Bourdieu (1973) cuando inquiere “¿existe la opinión pública?”, y responde que los sondeos y encuestas de opinión son una herramienta útil para reforzar un efecto de consenso, a partir de la (falsa) existencia de una opinión pública unánime y coherente. Lo que los analistas e investigadores podemos entender como los "límites" o las falsas expectativas que el empleo de esta herramienta genera, los asesores presidenciales y gobernantes la emplean, sin tantos miramientos, para corroborar que cuentan con un respaldo y tomar decisiones justificadas en la demanda "de la gente".

En este trabajo, al reconocimiento general de los límites de la utilización de este tipo de herramientas, se le sumaron las consideraciones respecto de su empleo en un escenario dictatorial. Con esta precaución metodológica encaramos la lectura de los informes realizados por la SIP y por la SIDE, manteniendo una mirada crítica que nos obligaba a recordar la amenaza y el terror que posiblemente condicionaron a quienes aceptaban responder estos sondeos y encuestas de opinión. Sin embargo, el recorrido cronológico de los informes nos permitió advertir que, pese a esos condicionamientos, las respuestas no fueron siempre las mismas así como tampoco fueron todas contemplativas o evidenciaron sólo adherencia al régimen, como hubiese podido suponerse. Por el contrario, la lectura de este material permite evidenciar momentos de mayor y menor crítica al Proceso y a la gestión presidencial, y sobre todo permiten reconocer las "expectativas" de la población sobre el futuro (la anhelada "apertura política”), que no coincidían con los planes del régimen. 
Finalmente, nos propusimos analizar este material para contribuir a delinear la dimensión productiva de la dictadura, a contrapelo de una instalada lectura académica que presenta a los militares como si sólo fueran "portadores de una identidad tosca, constreñida al uso instrumental de la fuerza", una mirada que elude otras dimensiones que también estuvieron presentes (Crenzel, 2010, p. 106), como el empleo de la estrategia psicosocial que hemos analizado en nuestro artículo, orientada a construir, renovar o reforzar el consenso y legitimidad de la población al régimen militar.

\section{Bibliografía}

Águila, G. (2013). Las tramas represivas: continuidades y discontinuidades en un estudio de caso. La Dirección General de Informaciones de la Provincia de Santa Fe, 1966-1991. Sociohistórica, 31.

Bourdieu, P. (1973). La opinión pública no existe. Les temps modernes, 318, 1292-1309.

Bourdieu, P. (2000). Cuestiones de Sociología. Istmo, 166, 220-232.

Canelo, P. (2008). El proceso en su laberinto. La interna militar de Videla a Bignone. Buenos Aires: Prometeo.

Canelo, P. (2012). Los efectos del poder tripartito. La balcanización del gabinete nacional durante la última dictadura militar argentina. Probistoria, 15(17), 129-150.

Canelo, P. (2015). La importancia del nivel municipal para la última dictadura militar argentina. Un estudio a través de sus documentos reservados y secretos (1976-1983). HISTORIA, 2(48).

Calvo Vicente, C. (1995). El concepto de consenso y su aplicación al estudio del régimen franquista, Spagna Contemporánea, 7.

Carassai, S. (2013). Los años setenta de la gente común: la naturalización de la violencia. Buenos Aires: Siglo Veintiuno Editores.

Cheresky, I. (1998). La ciudadanía, la opinión pública y los medios de comunicación. Ciudadanía y política en la Argentina de los 90. En S. Villavicencio, H. Quiroga y P. Vermeren (Eds.), Filosofias, Estado democrático y ciudadania en Argentina y en Francia. Buenos Aires: Ed. Homo Sapiens.

Crenzel, E. (2010). Una encuesta de opinión pública en Tucumán bajo la dictadura. Una aproximación indicial. Telar, 7-8, 92-109. Disponible en: http://revistatelar.ct.unt.edu.ar/index.php/revistatelar/article/view/148.

Crenzel, E. (2013). Los años setenta de la gente común. La naturalización de la violencia, por Sebastián Carassai, Buenos Aires, Siglo XXI, 2013, 329 p. Nuevo Mundo Mundo Nuevo. Disponible en: http://journals.openedition.org/ nuevomundo/66159

Fontana A. (1984). Fuerzas Armadas, partidos políticos y transición a la democracia en Argentina, 1981-1983. Centro de Estudios de Estado y Sociedad, 28.

Foucault, M. (2007). Nacimiento de la biopolítica. Buenos Aires: Fondo de Cultura Económica.

Fridman, D. (2008). La creación de los consumidores en la última dictadura. Apuntes de Investigación del CECYP, 14.

Jelin, E. (2002). Introducción. Gestión política, gestión administrativa y gestión histórica: ocultamientos y descubrimientos de los archivos de la represión. En L. Da Silva Catela y E. Jelin (Comp.), Los archivos de la represión: documentos, memoria y verdad. Madrid: Siglo Veintiuno de España Editores.

Lvovich, D. (2006). Dictadura y consenso ¿Qué podemos saber? Puentes, 17, 41-45.

Lvovich, D. (2017). La llamada 'Revolución Argentina', las ciencias sociales y la opinión sobre la violencia. Algunas ideas e informaciones iniciales”. En prensa. 2017.

Maioli, E. (2013). El uso de los sondeos aplicados al conocimiento de la opinión pública. Una revisión de la propuesta crítica de Pierre Bourdieu. Reflexión académica en Diseño y Comunicación, 21(4), 148 - 152.

Novaro, M. y Palermo, V. (2003). La dictadura militar 1976/1983. Del golpe de Estado a la restauración democrática. Buenos Aires: Paidós.

O’Donnell, G. (1984). Democracia en la Argentina: micro y macro. En O. Oszlak, (comp.), "Proceso", crisisy transición democrática, Vol. (2), Buenos Aires: Centro Editor de América Latina. 
Poli, J. H. (1958). Accio\#n psicolo\#gica. Arma de paz y de guerra. Buenos Aires: Cï\#rculo militar argentino, Biblioteca del Oficial.

Poli, J. H. (1979). Estrategia psicosocial. Buenos Aires: Ci\# rculo militar argentino, Biblioteca del Oficial.

Quiroga, H. (2004). El tiempo del "proceso". Conflictos y coincidencias entre politicos y militares 1976-1983. Rosario: Edit. Homo Sapiens.

Risler, J. (2015). Acción psicológica, comunicación y propaganda durante la última dictadura argentina (1976-1983) (Tesis de Doctorado en Ciencias Sociales), Universidad de Buenos Aires, Argentina.

Saz Campos, I. (2014). Decir no sólo miedo y represión quiere decir que también el miedo y la represión formaron parte del franquismo. Entrevista con Ismael Saz Campos. Páginas Revista Digital de la Escuela de Historia, 6(10).

Schenquer, L. (2017). La cultura de la última dictadura argentina. Del dispositivo de control represivo al reconocimiento del instrumento para la construcción de consensos. Latin American Perspectives. En prensa.

Sirlin, E. (2006). La última dictadura: genocidio, desindustrialización y el recurso a la guerra (1976-1983). En S. de Luque et al., Pasados y Presentes. Política, economia y conflicto social en la historia argentina contemporánea. Buenos Aires: Dialektik.

Vinuesa Tejero, M. L. y Fernández Martín, E. (2014). Sondeos electorales y medios de comunicacio\#n: la opinio\#n de los expertos del mundo de la demoscopia. Estudios sobre el Mensaje Periodistico. 20(1), 567-584.

Vommaro, G. (2008). Lo que quiere la gente. Los sondeos de opinión y el espacio de la comunicación política en Argentina (1983-1999). Buenos Aires: Prometeo Libros.

Yannuzzi, M. de los Á. (1996). Politica y Dictadura. Rosario: Edit. Fundación Ross.

\section{Documentos Citados:}

“Análisis de la encuesta piloto. Junio 1970. Rosario y Santa Fe". Fondo DGI. Archivo Provincial de la Memoria de Santa Fe, UC Nro.409 C.

"Encuesta nacional sobre diálogo político". SIP, 1980. Paquete 54. BANADE-CONADEP.

"Encuesta Motivaciones Políticas II", 13/11/81. Fondo DGI, Archivo Provincial de la Memoria de Santa Fe. UC Nro. 458, legajo 9.

Mensaje SIDE, 17/06/81. Fondo DGI, Archivo Provincial de la Memoria de Santa Fe. UC Nro. 407, legajo 1).

"Plan de acción política de la propuesta de Unión Nacional". Secretaría General de la Presidencia, noviembre de 1977. Disponible en: http://www.cipol.org/pdfs/Planes-pol/Propuesta_Politica_de_la_Secretaria_General_de_la_P residencia.pdf (consulta: 18 de septiembre de 2018).

"Situación Psicosocial". SIP. Paquetes 8 y 9. BANADE-CONADEP: Informe del 23/03 al 14/04/81. Informe del 29/03 al 14/04/81. Informe del 6 al 12/05/81. Informe del 12 al 18/08/81. Informe del 19 al 25/08/81. Informe del 28/10 al 03/11/81. Informe del 11 al 17/11/81. Informe del 18/11 al 24/11/81.

"Sondeo de Opinión Pública", SIDE, 14 al 21/10/82. Paquete 9. BANADE-CONADEP.

"Sondeo Mensual sobre aspectos de la realidad nacional", Télam, 15/08 al 14/09/81". Paquete 15. BANADECONADEP.

\section{Notas}

1 Como por ejemplo destacamos los trabajos de Alain Rouquié de gran influencia entre sus contemporáneos, que diferenciaban las dictaduras latinoamericanas de los fascismos europeos por su carácter desmovilizador, por la ausencia de un partido único y, por ende, por la inexistencia de un programa articulador y de formación de consenso. Este tipo de análisis comenzó a ser revisado en los años 90 en sintonía con los nuevos enfoques sobre el franquismo, por ejemplo, entre otros regímenes dictatoriales (Schenquer, 2017).

2 Según los teóricos que analizaron la problemática del consenso en regímenes no democráticos como el franquismo, es importante reconocer dos aspectos centrales: que "no es un fenómeno espontáneo y que se da por descontado, sino que es inducido desde el poder” con el fin de alcanzar propósitos tales como obtener juicios positivos sobre el sistema 
y el poder político, y a su vez, propagar juicios negativos sobre los opositores, así como también interiorizar actitudes y comportamientos acordes al modelo que el régimen desea imponer (Calvo Vicente, 1995); y que debiera aplicarse exclusivamente a las políticas estatales de autolegitimación, nunca a las actitudes de la población (para las cuales hay otros términos al estilo de: apoyo, adhesión, consentimiento, etc.): "No tiene sentido emplear el término para definir las actitudes de los ciudadanos (...) que no se pueden reducir a la noción de consenso" por su carácter variable y hasta contradictorio (Saz Campos, 2014).

3 Tal como lo expresó en 1977 Ricardo Yofré, quien ocupó un lugar estratégico en la Secretaría General de la Presidencia de la Nación: "[La] legitimación significa consenso. Todo gobierno -de jure o de facto- se legitima, o pierde LEGITIMACIÓN, en la medida del consenso que obtiene en el desarrollo de su programa de acción. (...) Todo poder político está fundado en la opinión pues aun los gobiernos asentados en la fuerza dependen, para sostenerse, de la opinión favorable de quienes controlan directamente el uso de la fuerza. Opinión que, en el caso de las Fuerzas Armadas argentinas y particularmente el Ejército, está íntimamente conectada con el sentir de la ciudadanía y con la valoración, que ésta hace sobre la acción gubernamental”. "Plan de acción política de la propuesta de Unión Nacional”, noviembre de 1977. Además ver Canelo (2015).

4 Julia Risler escribió una tesis doctoral sobre el tema, titulada “Acción psicológica, comunicación y propaganda durante la última dictadura argentina (1976-1983)”, defendida en 2015. Allí analiza la génesis local de esta tecnología de gobierno, el contexto de su desarrollo en el marco de las doctrinas de guerra revolucionaria y de seguridad nacional, y la particularidad de su despliegue y aplicación durante la última dictadura. La tesis se publicará en formato libro en el año 2018.

5 Uno de los ideólogos locales fue el Coronel del Ejército Jorge Heriberto Poli, quien la definió, en un temprano libro publicado en 1958, como "el recurso de conducción que regula el empleo planeado de todos los medios que influyen sobre determinadas mentes sociales, a través de los más variados métodos y procedimientos, coadyuvando con los esfuerzos físicos en el logro de los objetivos establecidos" ( Poli, 1958, p. 24).

6 Debe señalarse que esta estrategia fue desarrollada bajo el influjo de doctrinas castrenses norteamericanas y francesas. También encontramos en su elaboración elementos provenientes del campo de la comunicación, la propaganda y la psicología tal como las premisas de la Mass Communication Research y de la psicología conductista y social. La acción psicológica también fue implementada en otros países vinculados a través del Plan Cóndor. Tenemos constancia que en Chile se ejecutó un programa de "preparación psicológica de la población para contrarrestar la acción marxista”, el cual comenzó a funcionar en noviembre de 1973 y fue elaborado por el psicólogo Hernán Tuane Escaff, quien tuvo a su cargo la asesoría civil del Departamento de Relaciones Humanas y Conducta Social de la Secretaría General de Gobierno.

7 Se conoce como "Archivo Banade" a un conjunto de documentos sobre represión cultural hallados en el año 2000 en el edificio del Ministerio del Interior -en el que había funcionado con anterioridad el Banco Nacional De Desarrollo- el cual fue entregado a la CONADEP. Por su parte, el Archivo de la Memoria de la Provincia de Santa Fe, "descubierto" en 1993, resguarda el material producido por la DGI, una delegación local de la SIDE que dependía de las directivas del gobernador de Santa Fe. Sobre características de los “archivos de la represión” véase Águila (2013) y Jelin (2002).

8 En los años cincuenta, sociólogos influenciados por la sociología funcionalista norteamericana y las teorías de modernización (José Miguens, Gino Germani) comenzaron a utilizar esta técnica (Vommaro, 2008, p. 72). El autor identifica a los sociólogos Julio Aurelio, Edgardo Catterberg y Manuel Mora y Araujo como los "padres fundadores" de la disciplina local en los años ochenta, muy influenciados por la sociología empírica norteamericana, y a Heriberto Muraro como "maestro" de los nuevos expertos en la materia. En los años ochenta los encuestadores crearon sus propias empresas de sondeos y muchos renunciaron a las empresas de estudios de mercado.

9 Por poner sólo un ejemplo, la revista Gente publicó el 29 de octubre de 1981 los resultados provisorios del "Gran plebiscito" lanzado unas semanas atrás, el cual consistió en un cuestionario sobre temas varios de la realidad nacional que los lectores debían completar y devolver por carta a la revista. Esta recibió, hasta el 3 de octubre, 1042 cartas. Son llamativas las respuestas que, según la revista, evidenciaban la existencia de una mayoría que consideró entre positiva y muy positiva la "acción antisubversiva" de las FF.AA. y que "el país no estaba preparado para la democracia” (en 1981). Pero sobre todo nos interesan las respuestas sobre la situación económica: la mayoría estuvo de acuerdo con que era necesaria "la privatización de las empresas del Estado" y "la elección de un sistema económico libre" (Gente, 1981). Pudimos comprobar que la SIP realizó paralelamente un informe sobre empresas del Estado: ENTEL y los ferrocarriles y los resultados no fueron muy distintos. Sobre ENTEL: figura como uno de los problemas más importantes de los porteños y "según la OP [opinión pública] la desestimación de la privatización de ENTEL no condice con los objetivos del PRN” (SIP. 6/05 al 12/05/81 y 11/11 al 17/11/81). Mientras que el tratamiento a la situación de los ferrocarriles es aún más impactante: la SIP señaló que tras un accidente ferroviario, Somos y La Prensa publicaron notas sobre "el déficit de las empresas del Estado". La SIP salió a medir la opinión pública y el informe que reunió los resultados indicaba "La OP demanda al gobierno cumplir con la privatización tan esperada” (SIP. 6/05 al 12/05/81).

10 Estos libros de formación militar en la estrategia de Acción Psicológica fueron escritos por el coronel del Ejército Jorge H. Poli, y en ellos destaca: "Los sondeos y encuestas de opinión pública, como también otros procedimientos técnicos de 
reunión, son imprescindibles para conformar un registro amplio y actualizado de los rumores circulantes, dimensionada cualitativamente la sinusoide de sus volúmenes y contenidos temáticos." (Poli, 1979, p. 141) y "la medición, sondeo o cateo de la opinión pública es un elemento de juicio sumamente valioso, como aporte sociométrico, para la realización de estudios psicosociales, ya que se trata de un concomitante que sirve para agitarlos" (Poli, 1958, p. 83).

11 Otros trabajos que analizan el uso de encuestas por regímenes dictatoriales son: Crenzel (2010) sobre la que realizo\# la SIP en la provincia de Tucuma\#n a ocho meses del golpe de Estado y a casi un an\#o del Operativo Independencia y Lvovich (2017) sobre la "Encuesta Piloto" realizada en Santa Fe durante el gobierno de Onganía por un instituto privado y en la que se midió "el apoyo o rechazo de la opinión pública sobre ciertas obras o gestiones de gobierno a efectos de complementar con la debida Acción Psicológica” (“Análisis de la encuesta piloto. Junio 1970. Rosario y Santa Fe”).

12 Pese a que estos sondeos fueron realizados luego del período de gobierno del General Viola que es el que aquí nos interesa, lo hemos incluido porque mide las consecuencias de las decisiones adoptadas en ese período.

13 Para este sondeo la SIDE envió un cuestionario conformado por 5 preguntas, indicó que se les pagaría a los encuestadores ( 5 en total) y que la muestra debía incluir a 100 personas de las ciudades de Rosario y Santa Fe (Mensaje SIDE. Fondo DGI, 17/06/81).

14 Viola fue la figura más cercana a Videla desde el comienzo. Ocupó cargos estratégicos que fueron acompañando el ascenso al poder del último (tanto desde 1975 como Jefe del Estado Mayor del Ejército y luego en julio de 1978 desde el cargo de integrante de la Junta Militar). Massera, la figura fuerte de la Armada, se convirtió en un personaje crítico de la gestión de Videla e impulsó su propia figura para sucederlo. En esa disputa por el poder, el almirante quedó aislado ya que la Armada negoció quitarle el apoyo bajo la condición de que Videla dejase de ocupar el doble cargo de presidente y de miembro de la Junta Militar. En 1978 fue saldada esta discusión con la designación del “cuarto hombre” (Canelo, 2008, p. 83).

15 Los "moderados" fueron el "núcleo estable del proceso", los que apoyaron la política económica de Martínez de Hoz y se aliaron, por momentos, con los "duros". Entre la fracción "moderada" se encontraban los "politicistas" o "dialoguistas" (grupo al que pertenecía Viola) que consideraban a los partidos políticos los interlocutores válidos, por lo que ofrecieron un apoyo tibio al proyecto de creación del Movimiento de Opinión Nacional (Canelo, 2008, pp. 162-163).

16 Los "duros" (o "señores de la guerra") eran predominantemente miembros de la Fuerza Aérea y el Ejército; rechazaban cualquier modo de acercamiento o diálogo con los civiles y eran fervientemente antiperonistas integrantes del bando "colorado". Entre ellos se encontraba Benjamin Menéndez que encabezó una rebelión contra Viola desde Córdoba (Canelo, 2008, p. 162).

17 Citas de los primeros discursos de Viola, extraídas del texto de Quiroga (2004, pp. 210-211).

18 En relación a la "marcha" del país, el 86,6\% declaraba que iba "bastante o muy mal”. Pero mientras que el 38,2\% percibía una "imagen de continuidad" con la gestión anterior, el 50,4\% descreía de esta continuidad (SIP, 12 al 18/08/81).

19 El informe también remarcaba la importante difusión del documento elaborado por Frondizi y Frigerio, dirigentes del Movimiento de Integración y Desarrollo, MID, el cual contenía críticas al equipo económico anterior y un "apoyo condicionado" a la gestión Viola, que consideraban "más sensible a los problemas y más dispuesta a dialogar y escuchar” (SIP, 06 al 12/05/81).

20 El informe advertía acerca de las “expectativas” que suscitaba en la población la Marcha del Pan y del Trabajo a realizarse el 7 de noviembre, observando la posibilidad de que en el interior del país estas marchas pudieran derivarse a los templos y traducirse en ollas populares con características más “espectaculares” que las mismas misas (SIP, 28/10 al 03/11/81).

21 En el sondeo mensual se destaca que frente a la pregunta sobre "la evolución de la situación económica": la opinión predominante fue que la economía iba a empeorar (35,9\%), seguida por los que indicaban que se mantendría igual $(28,2 \%)$ y la minoría que pensaba que mejoraría $(24,4 \%)$ ("Sondeo Mensual sobre aspectos de la realidad nacional", $15 / 08$ al 14/09/81).

22 Tal como se destaca en la introducción de todos los informes "Situación Psicosocial": "los temas y/o tópicos deben ser tenidos en cuenta como contribuyentes - no siempre completos- para la instrumentación de Acciones Comunicacionales aisladas o campañas de Comunicación Social que tiendan a modificar o afirmar determinadas actitudes de los públicos".

23 Los llamados "moderados" (Videla-Harguindeguy) habían implementado un diálogo "con la civilidad" e invitado a participar a miembros de partidos políticos pero a "título personal”. Buscaban constituir una "Unión Nacional” que, lejos de discutir el calendario electoral, sirviera para acordar la convergencia cívico-militar que defendería la no revisión de lo actuado en la "lucha antisubversiva" y sobre todo que fijaría la participación de las Fuerzas Armadas en el futuro sistema de gobierno. Estos "diálogos" fueron lanzados en forma paralela a los llamados a formar el MON (Movimiento de Opinión Nacional), una estructura o partido único que "heredaría” el Proceso en reemplazo de los partidos políticos (Quiroga, 2004, p. 200; Canelo, 2008, pp. 162-163).

24 Los llamados "duros" se oponían a construir alianzas con civiles y propiciaban entregar el poder una década más tarde (en 1991). Para ese entonces ya habrían modificado la Constitución Nacional y constituido el "Consejo de la República”, un organismo conformado por las Fuerzas Armadas para el arbitrio de la democracia (Canelo, 2008, p. 162). 
25 Cabe destacar que si bien fueron invitados presidentes de diferentes estructuras partidarias a entrevistarse con el ministro del Interior Harguindeguy, el acento del gobierno estaba puesto en los partidos de centro y de derecha. En estas entrevistas el ministro les comunicó a los partidos la intención oficial de que confluyeran en una estructura común (el Movimiento de Opinión Nacional) y más tarde, que se transformaran en "nuevos partidos con ideas nuevas". En la práctica estas demandas implicaban el no reconocimiento a los partidos en su estructura tradicional, y el intento de que formaran un partido formado por una dirigencia "amiga" y heredera del Proceso (Yannuzzi, 1996, p. 424).

26 A los ministerios existentes fueron agregados los de Obras y Servicios Públicos, Industria y Minería, Agricultura y Ganadería, Comercio e Intereses Marítimos y Salud Pública y Medio Ambiente (Canelo, 2015).

27 La encuesta constaba de varias preguntas, entre ellas: “¿Ud. considera que con el cambio de Gobierno se inaugura una etapa de mayores libertades políticas o no?" un 59,8\% respondió que "Sí” y sólo un 23,8\% que "No" (el resto se dividió entre un $16 \%$ que dijo "No saber" y un $0,4 \%$ que "No responde"); y otra de las preguntas era: "Según el presidente Viola durante su mandato se habilitará a los partidos políticos. Ahora bien, ¿Ud. cree que los partidos políticos actuales son los instrumentos válidos para representar las inquietudes de la población?” en este caso los que respondieron afirmativamente fueron apenas el 32,8\%, mientras que 10,6\% indicó “más o menos", 15,6\% que "no sabe", 0,8\% "no responde" y 40,2\% dijo contundentemente que "No" (SIP, 29/03 al 14/04/81).

28 Más allá de esta aclaración sobre la falta de representatividad de la muestra, cabe aclarar que no es el objetivo del presente artículo conocer hasta qué punto los sondeos y encuestas reflejaban la realidad específica de 1981. Nuestro análisis es sobre el uso que la dictadura hizo de esta herramienta al momento de ponderar el impacto de ciertas decisiones en la opinión pública, y obtener información que permita incluir, corregir o ajustar las acciones por parte del Ejecutivo.

29 Ni la SIP ni la SIDE midieron la opinión de la población con respecto a la formación en julio de 1981 de la Multipartidaria. De haberlo hecho, una posible comparación entre estos resultados y las cifras mostradas que evidencian el bajo grado de inserción (o aceptación) de los partidos políticos en la sociedad, permitiría analizar si estas estructuras se encontraban deslegitimadas por un proceso interno y propio a la "suspensión" de sus actividades, o bien si habían generado opiniones reticentes por su participación en el "diálogo” convocado por el régimen.

30 Además véase el análisis sobre la situación de la viuda de Perón: "Si bien una gran parte de la OP [opinión pública] general está demostrando interés cada vez menor por la situación de la ex- presidenta María E. Martínez de Perón, algunos grupos de opinión seguirían atentamente las causas sobre Precruzada y Cruzada de Solidaridad Justicialista" (SIP, 29/03/81 al 14/04/81; 6/05/81 al 12/05/81); y sobre la censura al periódico peronista Línea (SIP. 6/05/81 al 12/05/81).

31 Para una enumeración completa de los diez temas véase la próxima sección de este trabajo. (SIP, 29/03/81 al 14/04/81).

32 Entre quienes apoyaban había "viejos adherentes" y algunas nuevas "incorporaciones”, más mujeres (45,6\%) que varones $(41,5 \%)$, y un porcentaje mayor de población madura (52,6\% de mayores de 44 años) que de jóvenes, entre quienes prima el rechazo (un 44\% de encuestados entre 24-44 años). Entre los que no apoyaban, la mayor parte "adhirió a él en el pasado, restándole apoyo en su transcurso”. Mientras que el promedio de rechazo de la población dedicada al comercio, industriales, empresarios, obreros, profesionales y empleados rondaba el 49,7\%. El total de encuestados: 500 (SIP, 12 al 18/08/81).

33 Se destaca que "mantienen perturbado el estado anímico de los diversos sectores de la OP [opinión pública]" cuestiones que básicamente no había cambiado respecto del período anterior como la prohibición de canciones populares y programas de TV, la violenta represión policial contra periodistas en una manifestación estudiantil, y los rumores de suba del dólar y de renuncias en el gabinete económico (SIP, 19 al 25/08/81).

34 Entre los juicios positivos de los encuestados, se destacan las siguientes afirmaciones: "es respetuoso de las libertades" (dijo un miembro del clero), "actúa con mesura" (indicó un productor rural), "tiene buenas intenciones" (señaló una ama de casa). Entre los negativos, que son muchísimos más, predominan los siguientes: "no se preocupa por el hambre de los trabajadores" (afirmó un obrero), "sin poder de decisión” (destacó una ama de casa), "los militares destruyeron el país" (dijo un abogado), "no se sabe bien qué es lo que hace ni quién manda” (apuntó una ama de casa), "toda la ciudadanía argentina está confundida. No se sabe adónde vamos” (señaló un empresario), "le falta personalidad, imagen de firmeza y seguridad para transmitir optimismo al pueblo" (dijo un geólogo). ("Sondeo Mensual sobre aspectos de la realidad nacional", $15 / 08$ al 14/09/81). 